\title{
Cervical Ripening for Induction of Labor: A Randomized Comparison between Vaginal Misoprostol versus Foley's Catheter Placement in a Nigeria Tertiary Hospital
}

\author{
Matthew Igwe Nwali1*, Joseph Agboeze ${ }^{1}$, Vitus Okwuchukwu Obi ${ }^{1}$, Arinze C. Ikeotuonye1, \\ Ikechukwu Ogwudu Ugadu', Emmanuel Ajuluchukwu Ugwa ${ }^{2}$
}

\begin{abstract}
${ }^{1}$ Department of Obstetrics and Gynecology, Federal Teaching Hospital, Abakaliki, Nigeria
${ }^{2}$ Department of Obstetrics and Gynecology, Federal Medical Center, Birnin Kudu, Nigeria

Email: *matthewigwenwali@yahoo.com
\end{abstract}

How to cite this paper: Nwali, M.I., Agboeze, J., Obi, V.O., Ikeotuonye, A.C., Ugadu, I.O. and Ugwa, E.A. (2021) Cervical Ripening for Induction of Labor: A Randomized Comparison between Vaginal Misoprostol versus Foley's Catheter Placement in a Nigeria Tertiary Hospital. Open Journal of Obstetrics and Gynecology, 11, 252262.

https://doi.org/10.4236/ojog.2021.113024

Received: January 18, 2021

Accepted: March 8, 2021

Published: March 11, 2021

Copyright $\odot 2021$ by author(s) and Scientific Research Publishing Inc. This work is licensed under the Creative Commons Attribution International License (CC BY 4.0).

http://creativecommons.org/licenses/by/4.0/ (c) (i) Open Access

\begin{abstract}
Background: Cervical ripening is prerequisite of successful induction of labor. Vaginal misoprostol and Foley's catheter placement have been widely used for this purpose but the data are not always sufficient. We attempted to determine which (misoprostol versus Foley's catheter) is more effective/safer in Nigerian setting. Methods: A randomized controlled trial was performed at Federal Teaching Hospital Abakaliki, Nigeria, involving 135 term pregnant women requiring cervical ripening and labor induction. Participants were randomly allocated to misoprostol versus catheter group. The following were recorded/measured/analyzed: Bishop's score, age, parity, body mass index, gestational age, labor duration, indication, oxytocin use, mode of delivery, and Apgar score. Chi square test and t test were used where appropriate. Results: At 24 hours, all of misoprostol group were either in labor, had ripe cervix, or had delivered, whereas $35.4 \%$ of catheter group had still unripe cervix $\left(x^{2}=\right.$ 29.856, $P=0.0001)$. Misoprostol group was less likely to require oxytocin infusion $\left(x^{2}=52.600, P=0.0001\right)$ and less likely to require cesarean delivery (cesarean: misoprostol versus catheter: $11 \%$ versus $\left.34 \%\left(x^{2}=9.800, P=0.001\right)\right)$. Total medical cost for misoprostol was less than that of catheter $\left(x^{2}=14.703\right.$, $P=0.0001)$. Conclusion: $50 \mu \mathrm{g}$ vaginal misoprostol, compared with catheter placement, was more effective, cheaper, and safe as a procedure of cervical ripening before induction of labor.
\end{abstract}

\section{Keywords}

Cervical Ripening, Labor Induction, Misoprostol, Balloon Catheter 


\section{Introduction}

Induction of labor requires cervical ripening and many strategies have been reported for cervical ripening, among which misoprostol and Foley's catheter are widely known. Which is better of the two is not always determined, especially in Nigeria, thus we attempted to determine it as well as the benefits and harms of the methods [1]. In about $10 \%$ of all pregnancies, the cervix is unfavorable and there are conflicting reports on the relationship between the Bishop's score (cervical changes) and the success of labor induction. Some showed inverse while others showed no relationship [2] [3] [4].

There are conflicting reports on the efficacies, cost and safeties of the use of Foley's catheter and misoprostol for cervical ripening and induction of labor. Some reported in favor of catheter, others reported in favor of misoprostol while some reported similar effects [2] [5]-[10]. Some studies however demonstrated increased risk of maternal and fetal infection with the use of catheter [11] [12].

Studies have also demonstrated increased risk of hyper stimulation, non-reassuring fetal heart rate pattern, admission into the newborn unit and uterine rupture associated with misoprostol [13] [14] [15] [16] [17]. The case of uterine rupture was recorded in the study that used $100 \mu \mathrm{g}$ of misoprostol [17]. The rate of induction is on the increase, $35.5 \%$ in Sri Lanka, $24.5 \%$ in USA, 33\% in Europe, $12.7 \%$ in Ibadan Nigeria and $11.5 \%$ in Abakaliki [3] [18]. Studies on maternal mortality in Ebonyi State have reported high maternal mortality ratios both in the rural and urban areas where uterine rupture was reported as a major cause due to injudicious use of uterotonics [19] [20] [21] [22].

\section{Objectives:}

1) To determine and compare the efficacies and safeties of misoprostol and balloon catheter for cervical ripening and induction of labor.

2) To determine the effective and safe dosage of misoprostol for cervical ripening and induction of labor for our clients.

3) To determine and compare the cost of each method.

Research Questions: Is there a difference in the efficacy, cost and safety of intracervical Foley's catheter balloon and intravaginal misoprostol for cervical ripening and induction of labor?

\section{Materials and Methods}

\subsection{Background}

Ebonyi state is a low resource state, it has one urban and one semi-urban setting while the rest are rural settings. Ignorance and poverty is prevalent and with tendency to high parity and low acceptance rate for contraception and family planning. The Federal Teaching Hospital is the tertiary hospital located at Abakaliki the capital city of the state. It serves as the referral center for the state and some parts of the surrounding states. Most of the labor induction and cervical ripening in the state take place in the center. 


\subsection{Study Population}

This is a randomized controlled trial that included all parturients requiring cervical ripening at term in the Obstetrics and Gynecology unit of the Federal Teaching Hospital, Abakaliki during the study period. The parturients were recruited by simple random sampling method (lucky dip) till the required sample size was obtained. The exclusion criteria were those who refused consent, preterm delivery, vaginal infection, non-cephalic presentation, multiple gestation, low lying placenta/previa, vaginal bleeding, previous cesarean section and ruptured membranes. Parturients who gave consent, had low bishop score $(\leq 5)$, term singleton cephalic presenting fetus with intact membranes and no contraindication to vaginal delivery were recruited into the study. The purpose and methods of the study as well as the possible adverse events that can occur were explained to the parturients in details and informed consent obtained prior to enlisting them into the study.

\subsection{Sample Size Calculation}

Considering a formula for sample size calculation in a randomized clinical trial by Marlies Noordzii et al. [23]

$$
n=2\left[(a+b)^{2} \delta^{2}\right] /\left(\mu_{1}-\mu_{2}\right)^{2}
$$

$$
\begin{aligned}
n & =62.8 \\
& =63 \text { parturients in each group giving a total of } 126 \text { parturients. }
\end{aligned}
$$

A response rate of about $90 \%$ was anticipated thus the final sample size was; $N=126 / 0.9=140$, i.e. 70 parturients per arm.

\subsection{Study Design}

This was a randomized controlled trial made up of two arms or groups. The first arm or group -1 had cervical ripening with intra-cervical extra-amniotic Foley's balloon catheter while group -2 had cervical ripening with intra-vaginal misoprostol. The parturients were selected by simple random sampling method and recruited into the arms of the study. Each parturient picked by simple lucky dip from a pool of folded papers with inscription group 1 or group 2 in a bag in a double blinded manner and were recruited into the group picked among the two arms of the study.

\subsection{Procedure}

The Bishop's score of the cervix was accurately determined and documented before cervical ripening. Bishop's score of $\geq 6$ was considered ripe or favorable for induction.

Catheter arm

Size 18 Foley's catheter was introduced through the cervix to the extra-amniotic space with the aid of a speculum and sponge-holding forceps by strict aseptic technique. The vulva was swabbed thoroughly with chlorhexidine swab before 
the procedure. Sterile speculum was inserted into the vagina to expose the cervix. With good light source, the catheter was carried with sterile sponge holding forceps making sure it does not touch the vaginal wall and introduced through the cervical os into the uterine cavity but in the extra-amniotic space. The catheter balloon was then inflated with $30 \mathrm{ml}$ of sterile water for injection. The catheter was then placed with minimal traction by strapping the end to the inside of the parturient's thigh. The parturient was observed for 12 hours after which it was removed if it has not fallen off. The procedure was repeated for another 12 hours if the cervix is not ripe with the first procedure. The process was considered to have failed if the cervix is not ripe after the second procedure and another method of cervical ripening was employed. At the expulsion or removal of the catheter, the Bishop's score was reassessed to determine cervical ripening and those whose cervixes were ripe were observed for two hours for evidence of spontaneous labor.

Misoprostol arm

In this arm, $50 \mu \mathrm{g}\left(1 / 4^{\text {th }}\right.$ of $\left.200 \mu \mathrm{g}\right)$ misoprostol tablet was placed in the posterior fornix of the vagina every 6 hours for a maximum of 4 doses. At each insertion the vulva was thoroughly swabbed with chlorhexidine swab and aseptic procedure was maintained. The parturient was monitored closely to rule out hyper stimulation. Before the insertion of subsequent doses, the parturient was re-evaluated for the presence of contractions and Bishop's score noted. Those with ripe or favorable cervix and or contractions had no further insertions. Those with unripe cervix had further insertions to a maximum of 4 doses, while those with ripped cervix were observed for 2 hours to see if they will go into active labor.

Both arms received prophylactic antibiotics of ampiclox. Those who transformed into active labor within 2 hours of observation were transferred into the labor room and their labor monitors with partograph with the aim of at least 1 $\mathrm{cm}$ cervical dilatation per hour, failure of which the labor was augmented with intravenous oxytocin. Those who did not transform into active labor within this period had synchronous induction of labor with oxytocin and artificial rupture of membranes and partograph monitoring. Oxytocin titration for induction of labor was done with $10 \mathrm{IU}$ (international unit) of oxytocin in 1 liter of normal saline starting with 10 drops per minute and escalating by 10 drops every 45 minutes till end point of 3 strong uterine contractions in 10 minutes or 60 drops per minute. The procedures was considered to have failed if after 24 hours the cervix was not ripe for induction or after 16 hours of induction, adequate uterine contractions leading to vaginal delivery was not achieved or the procedure ended in caesarean section.

\subsection{Data Collection}

Information on age, height, weight, parity, gestational age, Bishop's score, indications for induction, mode of delivery, complications, apgar scores and cost 
were obtained. The information obtained was recorded in the data collation sheet designed for the study.

\subsection{Data Analysis}

The coded data was fed into the computer using IBM SPSS program (2007), Illinois USA version 20 and analysis done. Descriptive and inferential statistics were used for quantitative variables, chi square was used to compare categorical variables while t-test was used to compare mean. $P<0.05$ was considered significant.

\subsection{Ethical Issues}

Full ethical approval was obtained from the Research and Ethics Committee (REC) of Federal Teaching Hospital, Abakaliki where the study was conducted in conformity with the Helsinki Declaration (REC No. 24/02/2015-22/071015). The study was also registered with the PRS of clinicaltrial.gov (Protocol ID: NCT02574338, Unique ID: MSFC-2015-CT). Informed consent was obtained from the parturients before recruitment into the study and confidentiality was ensured.

\section{Results}

A total of 135 parturients requiring cervical ripening and induction of labor for various indications were recruited by simple lucky dip into the study in a randomized pattern into two groups $1 \& 2$. There was no difference in the maternal age, parity, body mass index and gestational age at cervical ripening between the groups $p>0.05$ (Table 1 ).

The commonest indication in the study for cervical ripening and induction of labor was postdate pregnancy (70.4\%), followed by preeclampsia (20\%) (Table 2). At 12 hours, $60 / 70$ (85.7\%) of the parturients that received misoprostol were either in labor or had their cervix ripe already after one or two insertion/s. Among the parturients that had catheter only 21/65 (32.3\%) had their cervix ripe and none went into spontaneous labor. This difference was significant $\left(x^{2}=\right.$ 40.055, $p<0.0001$ ) (Table 3). At 24 hours, all parturients in the misoprostol group had delivered or in labor had ripe cervix while the catheter group had 23/65 (35.4\%) parturients whose cervix were not ripe. This was also significant $\left(x^{2}=\right.$ 29.856, $p<0.0001$ ) (Table 3 ).

The age and parity of the parturients had significant effect on the outcome of cervical ripening and labor induction while body mass index and gestational age did not (Table 4). The time taken for the cervix to ripe as shown by the number of insertions received by parturients had very significant effect on the duration of labor $\left(\mathrm{x}^{2}=38.024, p<0.0001\right)$ (Table 5).

Majority of the parturients in the misoprostol group (60.0\%) did not require the use of oxytocin in their labor and this was very significant. $\left(x^{2}=52.600, p<\right.$ 0.0001) (Table 6). 
Table 1. Sociodemographic characteristics of the parturients.

\begin{tabular}{cccccc}
\hline Variable & Catheter group & Misoprostol group & Total & $\mathrm{X}^{2}$ & $P$ \\
\hline Age & & & & & \\
$20-24$ & 7 & 24 & 17 & & \\
$25-29$ & 23 & 24 & 47 & 0.0725 & 0.7877 \\
$30-34$ & 23 & 10 & 20 & & \\
$35-39$ & 10 & 2 & 4 & & \\
$40-44$ & 2 & 24 & 82 & & \\
Parity & & 44 & 89 & 0.4622 & 0.4965 \\
1 & 18 & 2 & 4 & & \\
$1-4$ & 45 & 13 & 30 & & \\
$\geq 5$ & 2 & 30 & 62 & 0.0921 & 0.8645 \\
Body Mass Index & 17 & 28 & 43 & & \\
$18.5-24.9$ & 32 & & & & \\
$25.0-29.9$ & 15 & 9 & 12 & & \\
$\geq 30$ & & 20 & 31 & 0.3514 & 0.5533 \\
Gestational age & 3 & 41 & 92 & & \\
$<38$ weeks & 11 & & &
\end{tabular}

Table 2. Indication for cervical ripening/induction of labor.

\begin{tabular}{ccccc}
\hline Indication & \multicolumn{2}{c}{ Group } & Total & $\%$ \\
\hline & Catheter & Misoprostol & & \\
\hline Postdate & 52 & 43 & 95 & 70.4 \\
Preeclampsia & 10 & 17 & 27 & 20.0 \\
Fetal death & 1 & 2 & 3 & 2.2 \\
Others & 2 & 8 & 10 & 7.4 \\
\hline
\end{tabular}

Table 3. Cervical ripening at 12 and 24 hours.

\begin{tabular}{|c|c|c|c|c|c|c|}
\hline \multirow[t]{2}{*}{ Catheter } & \multicolumn{4}{|c|}{ Misoprostol } & \multirow[t]{2}{*}{$x^{2}$} & \multirow[t]{2}{*}{$p$} \\
\hline & Riped & Unriped & Riped & Unriped & & \\
\hline \multicolumn{7}{|l|}{ @ 12 hours } \\
\hline & 21 & 44 & 60 & 10 & \multirow{2}{*}{40.055} & \multirow{2}{*}{$<0.0001$} \\
\hline & $32.3 \%$ & $67.7 \%$ & $85.7 \%$ & $14.3 \%$ & & \\
\hline \multicolumn{7}{|l|}{ @ 24 hours } \\
\hline & 42 & 23 & 70 & \multirow{2}{*}{0} & \multirow{2}{*}{29.856} & \multirow{2}{*}{$<0.0001$} \\
\hline & $64.6 \%$ & $35.4 \%$ & $100 \%$ & & & \\
\hline
\end{tabular}

The parturients in the misoprostol group had less failed procedure (11.4\%) compared to those of the catheter group (33.8\%). The difference was significant. Most of the failed procedure misoprostol group was due to non-reassuring fetal heart rate $(87.5 \%)$ (Table 7 ).

There was no difference in apgar scores of the two groups (Table 8). The mean cost for group 1 that had catheter was USD5 \pm 1 while that of group 2 that received misoprostol was USD2 \pm 1 . This was very significant ( $\mathrm{t}$-test $=14.703, p$ $\leq 0.0001)$ (Table 9). 
Table 4. Sociodemographic variables and cervical ripening at 12 hours.

\begin{tabular}{ccccccc}
\hline Variable & \multicolumn{2}{c}{ Catheter } & \multicolumn{2}{c}{ Misoprostol } & $\boldsymbol{x}^{2}$ & $p$ \\
\hline Riped & Unriped & Riped & Unriped & & \\
\hline $20-24$ & 2 & 5 & 7 & 3 & & \\
$25-29$ & 5 & 18 & 19 & 5 & & \\
$30-34$ & 8 & 15 & 22 & 2 & & \\
$35-39$ & 6 & 4 & 10 & 0 & & \\
$40-44$ & 0 & 2 & 2 & 0 & 5.551 & 0.009 \\
Parity & & & & & & \\
0 & 2 & 16 & 16 & 8 & & \\
$1-4$ & 18 & 27 & 42 & 2 & & \\
$\geq 5$ & 1 & 1 & 2 & 0 & 10.854 & 0.002 \\
Body Mass Index & & & & & & \\
$18.5-24.9$ & 6 & 11 & 8 & 4 & & \\
$25.0-29.9$ & 12 & 20 & 27 & 3 & & \\
$\geq 30.0$ & 3 & 12 & 25 & 3 & 4.297 & 0.058 \\
Gestational age & & & & & & \\
$<38$ weeks & 1 & 2 & 8 & 1 & & \\
$38-40$ weeks & 4 & 7 & 18 & 2 & & \\
$>40$ weeks & 16 & 35 & 34 & 7 & 0.634 & 0.160 \\
\hline
\end{tabular}

Table 5. Time taken for the cervix to ripe and duration of labor.

\begin{tabular}{|c|c|c|c|c|c|}
\hline \multirow[t]{2}{*}{ Group } & \multirow{2}{*}{$\begin{array}{c}\text { Time of ripening } \\
\text { Hours (hrs) }\end{array}$} & \multicolumn{2}{|c|}{ Labor duration } & \multirow[t]{2}{*}{$x^{2}$} & \multirow[t]{2}{*}{$p$} \\
\hline & & $\leq 8 \mathrm{hrs}$ & $>8 \mathrm{hrs}$ & & \\
\hline \multicolumn{6}{|l|}{ Catheter } \\
\hline 1 insertion & 12 & 15 & 7 & & \\
\hline 2 insertions & 24 & 16 & 27 & & \\
\hline \multicolumn{6}{|l|}{ Misoprostol } \\
\hline 1 or 2 insertion & $6-12$ & 53 & 7 & & \\
\hline$\geq 3$ insertions & $12-24$ & 6 & 4 & 38.024 & $<0.0001$ \\
\hline
\end{tabular}

Table 6. Oxytocin use for induction/augmentation of labor.

\begin{tabular}{|c|c|c|c|c|}
\hline \multirow[t]{2}{*}{ Procedure } & \multicolumn{2}{|c|}{ Group } & \multirow[t]{2}{*}{$x^{2}$} & \multirow[t]{2}{*}{$p$} \\
\hline & Catheter & Misoprostol & & \\
\hline Induction & 56 & 18 & & \\
\hline$\%$ & 86.2 & 25.7 & & \\
\hline Augmentation & 5 & 10 & & \\
\hline$\%$ & 7.7 & 14.3 & & \\
\hline None & 4 & 42 & & \\
\hline$\%$ & 6.2 & 60.0 & 52.600 & 0.0001 \\
\hline
\end{tabular}

Table 7. Mode of delivery/indication for abdominal delivery.

\begin{tabular}{ccccccc}
\hline Route & \multicolumn{7}{c}{ Group } & $x^{2}$ & $p$ \\
\hline & Catheter & $\%$ & Misoprostol & $\%$ & & \\
\hline Vaginal & 43 & 66.2 & 62 & 88.6 & & \\
Abdominal & 22 & 33.8 & 8 & 11.4 & 9.800 & 0.001 \\
Indication & 8 & 36.4 & 7 & 87.5 & & \\
NRFR & 14 & 63.6 & 1 & 12.5 & & \\
Failure to progress & & & &
\end{tabular}

${ }^{*}$ NRHR-non-reassuring fetal heart rate. 
Table 8. Apgar scores at $1^{\text {st }}$ and $5^{\text {th }}$ minutes in the groups.

\begin{tabular}{|c|c|c|c|c|c|c|}
\hline \multirow[t]{2}{*}{ Apgar score } & \multicolumn{4}{|c|}{ Group } & \multirow[t]{2}{*}{$x^{2}$} & \multirow[t]{2}{*}{$p$} \\
\hline & Catheter & $\%$ & Misoprostol & $\%$ & & \\
\hline \multicolumn{7}{|l|}{$1^{\text {st }}$ minute } \\
\hline$\geq 7$ & 60 & 92.3 & 64 & 91.4 & & \\
\hline$<7$ & 5 & 7.7 & 6 & 8.6 & 0.035 & 0.242 \\
\hline \multicolumn{7}{|l|}{$5^{\text {th }}$ minute } \\
\hline$\geq 7$ & 64 & 98.5 & 68 & 97.1 & & \\
\hline$<7$ & 1 & 1.5 & 2 & 2.9 & 0.270 & 0.391 \\
\hline
\end{tabular}

Table 9. Mean cost per patient in each group.

\begin{tabular}{cccccc}
\hline Group & Number & Mean & std & t & $P$ \\
\hline Catheter & 65 & USD 5 & 1 & & \\
Misoprostol & 70 & USD 2 & 1 & 14.703 & $<0.0001$ \\
\hline
\end{tabular}

+USD—United States Dollar.

\section{Discussion}

A total of 135 parturients at term were recruited into this study, 65 parturients in the catheter arm and 70 in the misoprostol arm. At 24 hours, $64.6 \%$ of the catheter arm had ripe cervix while $35.4 \%$ had unripe cervix. In the misoprostol arm, all 70 (100\%) had ripe cervix at 24 hours. Thirty four percent of parturients in the catheter arm ended with abdominal delivery while only $11.4 \%$ of those in the misoprostol arm had abdominal delivery. These differences were statistically significant. This demonstrates the superiority of misoprostol to catheter for cervical ripening and subsequent induction of labor. There are varied reports from studies in the past, some reported similar efficacies while others reported superiority of prostaglandins [2] [5]-[10] [15]. A study in Lagos, Nigeria demonstrated the superiority of misoprostol to catheter for cervical ripening and induction of labor [15]. Other studies demonstrated shorter induction-delivery interval for misoprostol, low cesarean section rate and more likelihood of delivery within 24 hours [13] [14]. However, Tobawei and Oboro concluded from their study that the efficacy and safety of low dose misoprostol compared with balloon catheter in developing countries are undetermined [17].

The indication for abdominal delivery in the misoprostol arm was mainly due to non-reassuring fetal heart rate. There were similar reports from previous studies [14]. This study however demonstrated no difference in the apgar scores in the catheter and misoprostol groups. This shows that there may not be any net adverse effect of misoprostol on the neonatal outcome. This is however different from the study Martinez Kreft et al. which reported increased referral to neonatal intensive care for parturients that received $50 \mu \mathrm{g}$ of misoprostol for labor induction [13].

The age and parity of parturients had significant effect on the outcome. Young nulliparous parturients and those of lower parity had poorer outcome compared 
to those of higher parity. This may be due to poorer response to uterotonics that may be prevalent in this group [24] [25] [26]. The body mass index and gestational age however did not have significant effect on outcome. This may be due to local administration of the agents which are more likely to act locally. The parturients recruited in the study all had term pregnancies when adequate receptor elaboration assumed to have occurred.

The time taken for the cervix to ripe had direct effect on the labor duration. The parturients whose cervixes were ripe within 12 hours were more likely to deliver within 8 hours. This was statistically significant. Majority of the partuients in the catheter arm required oxytocin use for induction or augmentation of labor but those in misoprostol group went into active labor spontaneously, did not require oxytocin and were also more likely to deliver vaginally within 24 hours. This difference was very significant. There had been similar reports from previous studies [2] [15] [16].

There was no case of infection recorded during the study period. This may be due to the use of prophylactic antibiotics as well as strict asepsis ensured during the procedure. A systemic review with meta-analysis of 30 randomized controlled trials comparing mechanical methods with pharmacologic agents or placebo, however demonstrated increased maternal and neonatal infection among the parturients that underwent mechanical methods of cervical ripening [11]. A study in Italy however demonstrated the safety of cervical ripening with the Foley catheter with negligible risk of infection [12]. This study has also shown that the dose of misoprostol used was effective and safe as there was no case of uterine hyper stimulation or rupture recorded. The study in Lagos Nigeria reported uterine hyper stimulation and rupture but $100 \mu \mathrm{g}$ of misoprostol was used in the study [15].

Finally, the parturients in the catheter arm spent more than double the amount spent by those in misoprostol for cervical ripening, hence demonstrating the cost effectiveness of misoprostol compared to catheter.

\section{Conclusion}

We conclude that $50 \mu \mathrm{g}$ vaginal misoprostol, compared with catheter placement, was more effective, cheaper, and safe as a procedure of cervical ripening before induction of labor.

\section{Acknowledgements}

We sincerely appreciate the management and staff of Obstetrics and Gynecology unit of Federal Teaching Hospital, Abakaliki, Ebonyi State, Nigeria for their support in carrying out this study. We also wish to express our profound gratitude to the research assistants.

\section{Conflicts of Interest}

The authors declare no conflicts of interest regarding the publication of this paper. 


\section{References}

[1] Mozurkewich, E.L., Chilimingras, J.L., Berman, D.R., et al. (2011) Methods of Induction of Labour: A Systemic Review. BMC Pregnancy and Childbirth, 11, 84. https://doi.org/10.1186/1471-2393-11-84

[2] Sanchez-Ramos, L. and Delke, I. (2011) Induction of Labour and Termination of the Previable Pregnancy. In: James, D., Steer, P., Weiner, C.P., Gonik, B., Crowther, C.A. and Robson, S.C., Eds., High Risk Pregnancy: Management Options, 4th Edition, Saunders, St Louis, 1145-1168.

[3] Marconi, A.M. (2019) Recent Advances in the Induction of Labor. F1000Research, 8, 1829. https://doi.org/10.12688/f1000research.17587.1

[4] Leduc, D., et al. (2013) Induction of Labour. SOGC Clinical Practice Guideline No 296. Journal of Obstetrics and Gynaecology Canada, 35, 840-859.

https://doi.org/10.1016/S1701-2163(15)30842-2

[5] Ferdous, J., Khanam, N.N., Begum, M.R. and Akhter, S. (2009) Cervical Ripening: Comparative Study between Intracervical Ballooning by Foley's Catheter and Intravaginal Misoprostol Tablet. Journal of Bangladesh College of Physicians and Surgeons, 27, 5-12. https://doi.org/10.3329/jbcps.v27i1.4237

[6] Bello, F.A. and Akinyotu, O.O. (2016) Predictors of Successful Induction of Labour at a Tertiary Obstetric Service in Southwest Nigeria. Tropical Journal of Obstetrics and Gynaecology, 33, 143-148. https://doi.org/10.4103/0189-5117.192213

[7] Nyongo, D.D., Daloek, M. and Kahansim, M.L. (2020) Comparison of Low Dose Vaginal Misoprostol with Foley Catheter Balloon as Pre Induction Cervical Ripening Agent in Term Pregnancies. Annals of Medical Research and Practice, 1, 10. https://doi.org/10.25259/ANMRP 32020

[8] Shapoor, S., Seyedeh, R.Y.S., Shole, S., Farnaz, Z.V., Shamsi, Z., Deam, R. and Nasrin, S. (2019) Conservative Analysis of Vaginal Misoprostol and Foly Catheter in Cervical Ripening and Labor Induction. Journal of Obstetrics, Gynecology and Cancer Research, 4, 105-110.

[9] Cecilia, V., Maria, S.Q., Paula, G.A., Elisa, S., Enery, G.M., Alberto, G. and Ignacio, H. (2020) Prognostic Factors of Successful Cervical Ripeniong and Labor Induction in Late-Onset Fetal Growth Restriction. Fetal Diagnosis and Therapy, 47, 536-544. https://doi.org/10.1159/000503390

[10] Nazneen, S., Sultana, F. and Nahaer, K. (2012) Intravaginal Misoprostol versus Intracervical Foley Catheter for Pre-Induction Cervical Ripening and Their Outcome-A Comparative Study. Bangladesh Journal of Obstetrics \& Gynaecology, 27, 72-78. https://doi.org/10.3329/bjog.v27i2.29922

[11] Heinemann, J., Gillen, G., Sanchez-Ramos, L. and Kaunitz, A.M. (2008) Do Mechanical Methods of Cervical Ripening Increase Infection Morbidity? A Systemic Review. American Journal of Obstetrics and Gynecology, 199, 177-187. https://doi.org/10.1016/j.ajog.2008.05.005

[12] Cromi, A, Ghezzi, F., Tomera, S., Uccella, S., Lischetti, B. and Bolis, P.F. (2007) Cervical Ripening with Foley's Catheter. International Journal of Gynecology \& Obstetrics, 97, 105-109.

[13] Kreft, M., Krahenmann, F., Roos, M., Kurmanavicius, J., Zimmermann, R. and Ochsenbein-Kolble, N. (2014) Maternal and Neonatal Outcome of Labour Induction at Term Comparing Two Regimens of Misoprostol. Journal of Perinatal Medicine, 42, 1-7. https://doi.org/10.1016/j.ijgo.2006.10.014

[14] Abdel-Aleem, H. (2011) Misoprostol for Cervical Ripening and Induction of Labour: RHL Commentary. The WHO Reproductive Health Library, World Health 
Organization, Geneva. https://doi.org/10.1515/jpm-2013-0215

[15] Afolabi, B.B., Oyeneyin, O.L. and Ogedemgbe, O.K. (2005) Intravaginal Misoprostol versus Foley Catheter for Cervical Ripening and Labour Induction. International Journal of Gynecology \& Obstetrics, 89, 263-267.

https://doi.org/10.1016/j.ijgo.2005.02.010

[16] Oliveira, M.V., Oberst, P.V., Leite, G.K., Aquemi, A., Kenj, G., Leme, V.D. and Sass, N. (2010) Cervical Foley Catheter versus Vaginal Misoprostol for Cervical Ripening and Induction of Labour: A Randomized Clinical Trial. Revista Brasileira de Ginecologia e Obstetrícia, 32, 346-351.

https://doi.org/10.1590/S0100-72032010000700007

[17] Tobawei, T.O. and Oboro, V.O. (2003) Low Dose Intravaginal Misoprostol versus Intracervical Balloon Catheter for Pre-Induction Cervical Ripening. East African Medical Journal, 80, 91-94. https://doi.org/10.4314/eamj.v80i2.8652

[18] Osaheni, L.L., Azubuike, K.O., Chukwuemeka, A.I., Chikezie, N.O. and Leonard, O.A. (2014) Obstetric Outcome and Significance of Labour Induction in a Health Resource Poor Setting. Obstetrics and Gynecology International, 2014, Article ID: 419621. https://doi.org/10.1155/2014/419621

[19] Ezegwui, H.U., Onoh, R.C., Ikeako, L.C., Onyebuchi, A., Umeora, J., Ezeonu, P. and Ibekwe, P. (2013) Investigating Maternal Mortality in Public Teaching Hospital Abakaliki, Ebonyi State, Nigeria. Annals of Medical and Health Science Research, 3, 75-80. https://doi.org/10.4103/2141-9248.109511

[20] Umeora, O.U.J. and Egwuatu, V.E. (2010) The Role of Unorthodox and Traditional Birth Care in Maternal Mortality. Tropical Doctor, 40, 13-17. https://doi.org/10.1258/td.2009.080207

[21] Esike, C.O.U., Umeora, O.U.J., Eze, J.N. and Igberase, G.O. (2011) Ruptured Uterus: The Unabating Obstetric Catastrophe in South Eastern Nigeria. Archives of Gynecology and Obstetrics, 283, 993-997. https://doi.org/10.1007/s00404-010-1488-Z

[22] Umeora, O.U.J. and Ejikeme, B.N. (2006) Clinical Correlates and Trends in Hospital Maternal Mortality in Rural Nigeria. Journal of Obstetrics and Gynaecology, 26, 139-140. https://doi.org/10.1080/01443610500443451

[23] Noordzij, M., Tripepi, G., Dekker, F.W., Zoccali, C., Tanck, M.W. and Jager, K.J. (2010) Sample Size Calculations: Basic Principles and Common Pitfalls. Nephrology Dialysis Transplantation, 25, 1388-1393. https://doi.org/10.1093/ndt/gfp732

[24] Ray, G.A., Nicholson, S.M., Crankshaw, D.J. and Morrison, J.J. (2019) Maternal Parity and Functional Contractility of Human Myometrium in Vitro in the Third Trimester of Pregnancy. Journal of Perinatology, 39, 439-444. https://doi.org/10.1038/s41372-019-0312-2

[25] Ray, G.A., Crankshaw, D.J. and Morrison, J.J. (2019) Effects of Maternal Parity on Response of Human Myometrium to Oxytocin and Ergometrine in Vitro. The European Journal of Obstetrics \& Gynecology and Reproductive Biology, 242, 99-102. https://doi.org/10.1016/j.ejogrb.2019.09.006

[26] Kandemir, O., Dede, H., Yalvac, S., Aldemir, O., Yirci, B., et al. (2015) The Effect of Parity on Labor Induction with Prostagladin $\mathrm{E}_{2}$ Analogue (Dinoprostone): An Evaluation of 2090 Cases. Journal of Pregnancy and Child Health, 2, 149. https://doi.org/10.4172/2376-127X.1000149 